\title{
A mental health court hearing in Czechoslovakia
}

\author{
DAvid B. Mumford, Senior Registrar in Psychiatry, Department of Psychiatry, \\ University of Leeds, 15 Hyde Terrace, Leeds LS2 9LT
}

I was requested at short notice by Christian Solidarity International, a Swiss-based human rights group, to attend a court hearing in Czechoslovakia concerning a married couple who were being compulsorily detained in a psychiatric hospital. CSI had been alerted by a local Catholic activist, himself a former patient of the same hospital. The Czech authorities facilitated my attendance at the court hearing along with an English solicitor and provided an interpreter.

\section{Background history}

The couple's problems with the authorities began in 1966, shortly after becoming Seventh Day Adventists, when they received psychiatric diagnoses of 'paranoia religiosa adventistica' and were placed in a psychiatric institution. In 1967 parental rights to bring up their children were withdrawn.

Under the liberal regime of 1968 the couple were released, but subsequent Soviet 'normalisation' policies prevented reunion with their children. Attempts by the mother to regain custody of the children led to her second period of psychiatric detention.

In 1973, their fifth child was removed from them at birth and given for adoption. Their struggle to regain custody of their youngest child resulted in further psychiatric detentions until 1979 when they were released on condition that they received out-patient treatment.

Between 1979 and 1983 the couple accepted Modecate as out-patients at Prostejov. Both suffered increasing extrapyramidal side-effects. When they refused to comply with medication, a court in Prostejov ordered another period of detention in a psychiatric hospital.

An appeal lodged by the couple was eventually heard in May 1985 after the case had been transferred to Znojmo, allegedly because of its notoriety. When this court ordered further compulsory detention in hospital, they went into hiding with friends, from where, in 1987, they appealed to the Helsinki Review Conference for help.

In May 1989 the couple emerged from hiding, only to be promptly arrested and taken to Kromeriz psychiatric hospital. The new consultant psychiatrist, having made his assessment, applied to the court at Kromeriz for the couple's release.

\section{The court hearing}

The hearing took place on 13 July 1989 at Kromeriz, a handsome Baroque town in the farming country of central Moravia. It was presided over by a judge and two lay assessors with prosecution and defence represented.

The couple presented their petition to be released from all further psychiatric treatment. The consultant psychiatrist stated that he and two psychiatric colleagues at Kromeriz had examined the couple and unanimously agreed that neither was currently suffering from any psychiatric condition. He doubted the previous diagnosis of 'paranoia querulans' because, while this condition is usually progressive, the couple had remained free of symptoms since 1985 without medication. Any difficulties the couple had experienced might have arisen from 'social clumsiness' in their dealings with the authorities. Both had been under considerable stress which perhaps had resulted in certain pathological responses.

Summing up, the prosecutor supported the decision of the Znojmo court in 1985 based on contemporary medical recommendations but accepted current medical opinion that further treatment of both patients would be superfluous and moved that they be released from compulsory detention.

Following a half-hour recess, the judge pronounced that he accepted the psychiatric evidence in full and asserted that it would be contrary to principles of human rights to continue to detain the couple. He ordered their release from all further psychiatric treatment.

\section{My discussions after the hearing}

After the hearing I was able to speak at length with the couple, the consultant psychiatrist, the defence counsel, and the Catholic activist who had recently obtained release from the same hospital.

\section{(a) The mental and physical state of the couple}

The couple seemed to enjoy a close and affectionate relationship and showed no evidence of current psychiatric symptoms. The husband is an artist and art restorer, a man of wide interests, having studied 
Hebrew and Greek. The wife appeared to be the more vulnerable personality and at times clung to her husband for support.

It emerged that during their latest detention at Kromeriz psychiatric hospital they were given special privileges including frequent periods of daytime leave of absence. They had not been required to take medication; the wife had, however, received treatment for diabetes.

Their present state of good health was due to the fact that they had been in hiding for over three years and were not submitting to enforced medication. They described the extrapyramidal side-effects of the depot neuroleptics which they had previously been required to take.

\section{(b) Legal basis for psychiatric detention in Czechoslovakia}

According to defence counsel and the consultant psychiatrist, there are two routes to compulsory psychiatric detention, penal and civil.

Penal: Before a case goes to trial, an accused person may be referred to a psychiatric hospital for assessment or treatment, for a specified time or indefinitely. Following a trial, the court may order an offender to attend a psychiatric hospital as an in-patient or outpatient, for a specified time or indefinitely. There is provision for appeal if requested by the accused or his family.

Civil: A patient who is a danger to himself or to the community may be admitted and detained compulsorily in a psychiatric hospital under the Law of Protection of the Health of People. The detention is for an unlimited period, on the authority of one psychiatrist. The psychiatrist is required to register all such detentions with the Health Department of the district or regional National Committee. The patient or his relatives may appeal to the courts or to the Health Department for release from detention. There is no automatic review procedure.

\section{(c) The abuse of psychiatry}

All reported cases of psychiatric abuse in Czechoslovakia have involved the penal procedure for psychiatric detention. Defence counsel commented that although the courts have absolute discretion in these decisions, in practice the proposal of doctors involved is usually accepted. Most penal cases concerned drug addicts or alcoholics who had committed minor offences; of the remaining psychiatric cases he has dealt with, about $50 \%$ have had a religious element. The present case was a clear example of how troublesome individuals are referred for psychiatric treatment by the authorities who cannot punish them in any proper way.
The consultant psychiatrist, drawing on 25 years of experience in several psychiatric hospitals, stated that such cases were comparatively rare (an opinion confirmed by other informants in Czechoslovakia). He said that psychiatrists avoid involvement, so as not to come into conflict with the courts. Directors of psychiatric units dislike such cases because they highlight human rights issues and attract foreign media attention.

The psychiatrist said it was traditional to treat non-conformity with a diagnosis that would result in psychiatric detention. Originally this was a humanitarian ploy to prevent imprisonment, with no evil intentions on the part of psychiatrists. But it had cast a shadow on psychiatry, which he and his colleagues at Kromeriz now wanted to remove.

The Catholic activist commented that this was the first time he had known a psychiatrist recommend to a court that the accused be discharged from psychiatric care. Only six months previously, when he was trying to obtain release from psychiatric detention, a psychiatrist asked him: "Who am I, John Huss? Should I die at the stake?" (John Huss was a 14th century Bohemian Church Reformer and Czech national hero.) The consultant psychiatrist in the present case emphasised that the changing political climate in Czechoslovakia would allow any psychiatrist to do what he had done. Even so, he had decided to alter this couple's diagnosis only from paranoia to 'psychopathy' in the first instance, since it would have been 'too abrupt' to cancel the psychiatric diagnosis all at once.

The diagnoses of 'paranoia religiosa' and 'paranoia querulans' reflect a Central European diagnostic tradition derived from Kraepelin. The concept of paranoia has such wide and imprecise boundaries (like 'schizophrenia' in Soviet psychiatry) that it can easily encompass what in Britain would be labelled as personality disorder or plain eccentricity. Psychiatry pays a heavy penalty for unsatisfactory diagnostic categories, making itself vulnerable to both malevolent and well-intentioned abuse.

\section{(d) Did the presence of observers make a difference?}

The fact that this visit was facilitated by the Czech authorities represents a significant departure from previous practice, where Western observers have been prevented by various official measures from attending such hearings, and may indicate that times are changing.

Defence counsel later described these cases as the 'final echoes' of a passing era. Although our attendance at the hearing was much appreciated by the couple, it is not clear how much our presence may have influenced proceedings. The consultant psychiatrist said that the atmosphere was more formal than usual; he had not before been required to 
identify himself by producing his identity card, and by giving his date and place of birth. The reference in the judge's summing up to issues of human rights was probably for our benefit.

\section{Comment}

The outcome of the court hearing was probably assured beforehand or the Czech foreign ministry would not have approved our visit. The helpfulness of the Czech authorities may also be connected with Czechoslovakia's application to rejoin the World Psychiatric Association from which the Health Ministry had withdrawn in 1983.

The Czech psychiatrists to whom I spoke were keen to end their isolation and return to the main- stream of international psychiatry. Readmission to the World Psychiatric Association would strengthen their position.

It is impossible to measure the effect on this family of what they have experienced over the last 20 years. Pleasure at this couple's release from further psychiatric treatment must not be allowed to obscure the needless suffering to which this family has been subjected under the name of psychiatry.

\section{Acknowledgement}

I should like to thank Mr Paul Taylor, and Mr Simon George of Christian Solidarity International, for their contributions to this report.

\section{Miscellany}

\section{New publication}

Dream or Nightmare?: The Closure of Long-Stay Mental Hositals and Community Care. 1989. £3.50, plus 55p postage and packing. Available from: The Book Centre, Friends House, Euston Road, London NW1 2BJ (telephone 01-387 3601).

This report, prepared by a Quaker Social Responsibility and Education (QSRE) ad hoc group, studies those areas where solutions have been found to the crisis caused by the precipitate closure of mental hospitals and it has a number of recommendations to make about how Quakers (and others) can become involved in ensuring that the community can care for people with mental health problems before a hospital is closed.

\section{Friends of Tamil Nadu}

Dr Rathnam Viswanathan has retired from the NHS after 17 years as a consultant in North Wales. On a voluntary basis he is going to establish primary health care facilities in five small villages in his native Tamil Nadu, a state in Southern India, an area of great deprivation. Funds have already been raised by the people of North Wales to buy drugs and medicines to support his work and this campaign will continue.

\section{Accommodation service}

Doctor in the House is an accommodation service which specialises in providing accommodation for doctors and other medical personnel in private family houses. Further information: Doctor in the House, 19 Sispara Gardens, London SW18 1LG (telephone 018746786 and 01870 5949).

\section{Training packages}

Community Mental Health Workshop Series is a set of three workshop packs to help mental health workers, service users and volunteers explore key issues in developing effective community mental health services. The titles of each are: 'Making the Move', 'Working with the Community', and 'Getting the Message' and they can be purchased separately.

Further details of these and other training packages can be obtained from: Pavilion Publishing (Brighton) Ltd, Freepost (BR 458), 89 Havelock Road, Brighton BN1 1ZY (telephone 0273 563279).

\section{Silver anniversary}

Launched in 1965 by Dr Frank J. Ayd, International Drug Therapy Newsletter is embarking on its 25th year and is the oldest publication of its kind in the history of medicine. Its longevity is a testament to the important role psychoactive drugs have come to play in psychiatry. It publishes reports on new drugs and offers concise background perspectives as well as guidelines for usage.

\section{Dr Ashoka Jahnavi Prasad}

We were informed by Dr Prasad that he had been appointed Professor of Psychiatry at St Mary's University, Halifax, Canada and would be taking up his appointment in April 1990 (Psychiatric Bulletin, September 1989, 13, 527). We have learnt that Dr Prasad holds no appointment at, and is not associated in any way with, Saint Mary's University. 